\title{
Dominant distribution of mitochondrial DNA from recipient oocytes in bovine embryos and offspring after nuclear transfer
}

\author{
K. Takeda ${ }^{1}$,S. Takahashi ${ }^{2}$, A. Onishi ${ }^{1}$, Y. Goto $^{3}$, A. Miyazawa ${ }^{3}$ and H. Imai ${ }^{2 *}$ \\ Departments of ${ }^{1}$ Animal Breeding and Genetics and ${ }^{2}$ Animal Reproduction, National Institute of Animal Industry, Tsukuba, \\ 305-0901, Japan; and ${ }^{3}$ National Livestock Breeding Center, Fukushima, 961-8511, Japan
}

\begin{abstract}
In the process of nuclear transfer, heteroplasmic sources of mitochondrial DNA from a donor cell and a recipient oocyte are mixed in the cytoplasm of the reconstituted embryo. The distribution of mitochondrial DNA heteroplasmy in nuclear transfer bovine embryos and resultant offspring was investigated by measuring polymorphism in the displacement loop region of mitochondrial DNA using PCR-mediated singlestrand conformation polymorphism. Most offspring (20 of 21 calves) from recipient oocytes of undefined mitochondrial DNA genotypes showed different genotypes from the mitochondrial DNA of donor cells. The single calf that was an exception showed heteroplasmy, including the donor mitochondrial DNA genotype. Six cloned calves were produced from oocytes of a defined mitochondrial DNA genotype. All of these clonal members and various tissues showed only the mitochondrial DNA genotype derived from the oocyte. The mitochondrial DNA from donor cells appeared to be eliminated during early embryonic development; it gradually decreased at the early cleavage stages and was hardly detectable by the blastocyst stage. These results indicate that the genotype of mitochondrial DNA from recipient oocytes may become the dominant category of mitochondrial DNA in calves resulting from nuclear transfer.
\end{abstract}

\section{Introduction}

Mammalian mitochondrial DNA (mtDNA) is a doublestranded circular molecule of about $16.5 \mathrm{~kb}$, the genetics of which differ from that of the nuclear genome. mtDNA molecules are present in mitochondria that occupy a substantial portion of the cell cytoplasm. The number of mtDNA molecules in most types of cell is about $2 \times 10^{3}$ copies (Michaels et al., 1982). In contrast, the number of mtDNA molecules in a single oocyte, which has the largest amount of mitochondria in the cytoplasm, is about $2 \times 10^{5}$ (Michaels et al., 1982; Hauswirth and Laipis, 1985). At fertilization, mtDNA heteroplasmy occurs as a consequence of the spermatozoon, which has a small number (approximately 50-75) of mtDNA molecules, entering the mature oocyte (Hecht et al., 1984). However, after the egg has cleaved several times, mtDNA heteroplasmy is erased by the mechanism of exclusion of the sperm mtDNA from the egg cytoplasm (Kaneda et al., 1995; Sutovsky et al., 1996). The mtDNA shows inheritance by predominantly maternal cytoplasmic exchange (Gyllensten et al., 1985).

Spontaneous mutation of mtDNA has been observed and may cause mtDNA heteroplasmy. However, it appears that mtDNA heteroplasmy becomes homoplasmy by random distribution during oogenesis (bottleneck effect) (for review,

*Present address: Graduate school of Agriculture, Department of Reproductive Physiology, Kyoto University, Kitashirakawa, 606-8502 Japan. Received 6 July 1998. see Lightowlers et al., 1997). Pedigree analysis of a heteroplasmic displacement loop (D-loop) sequence variant in Holstein cows has demonstrated a return to homoplasmy within only one (Koehler et al., 1991) or two generations (Ashley et al., 1989). Jenuth et al. (1996) created lines of heteroplasmic mice carrying two mtDNA genotypes and showed that the bottleneck effect can be explained by random genetic drift in early oogenesis. Thus, it is likely that mtDNA heteroplasmy is unstable and shifts rapidly to a homoplasmic condition.

The procedure of nuclear transfer has been used to produce live offspring of several species, including mice, sheep, cattle, rabbits and pigs (for review, see Prather and First, 1990; Bondioli, 1993). Nuclear transfer embryos are produced by fusion of a nuclear donor cell with an enucleated recipient oocyte, giving rise to mitochondrial heteroplasmy in the reconstituted embryo. In these offspring, the nuclear genome is the same among clonal members, but presumably the mtDNA is different. Plante $e t$ al. (1992) reported that $m t D N A$ polymorphisms were found among four cloned Holstein bulls and suggested that the mtDNAs originated from recipient oocytes that were collected from different ovaries with different mtDNA genotypes. Steinborn et al. (1998a) reported that mtDNAs originating from donor cells were detected in cloned cattle, although one clone did show a reduction in donor cell mtDNA. Optimally, the origin of mtDNA should be determined in both the donor cell and the recipient oocyte to investigate the $\mathrm{mtDNA}$ genotype in nuclear transfer animals. 
The D-loop in mtDNA has a striking pattern of nucleotide substitution and is useful for evolutionary investigation of genetic variations (Greenberg et al., 1983). The D-loop region contains the regulatory sequences responsible for replication and transcription of the mitochondrial genome, such as the origin of heavy-strand replication (Clayton 1984). The lower stream of this replication origin is the most variable region in the D-loop (Horai and Hayasaka, 1990). Both Holstein and Japanese Black cattle are breeds classified as Bos taurus by mtDNA analysis (Watanabe et al., 1985; Kikkawa et al., 1995; Takeda et al., 1997). Although identification of the polymorphism on mtDNA has been conducted to distinguish between these breeds, no unique difference is observed, as is the case for other European cattle (Loftus et al., 1994). However, polymorphic variation was detected in all the cattle by direct sequencing or single-strand conformation polymorphism (SSCP) analysis in these reports. SSCP analysis allows detection of an unknown substitution, even if only a single base substitution has occurred (Orita et al., 1989; Suzuki et al., 1991), and can also easily detect heteroplasmy in genomes. This method can be used to identify reliably the mtDNA genotype of nuclear transfer embryos and cloned calves reconstituted from different mtDNA sources.

In this study, mtDNA heteroplasmy was determined in bovine nuclear transfer embryos and their offspring by detecting polymorphism in the D-loop using the PCR-SSCP method (Harumi et al., 1994; Takeda et al., 1997). In the first experiment, SSCP patterns in recipient oocytes and their ovaries were compared to determine whether the mtDNA genotypes were the same or different. In the second experiment, nuclear transfer embryos were produced using a recipient oocyte and a blastomere of a previously defined $m t D N A$ genotype, and mtDNA heteroplasmy and the origin of mtDNA in the nuclear transfer embryos and resultant offspring were analysed by PCR-SSCP.

\section{Materials and Methods}

\section{Collection of embryos and oocytes}

Donor embryos were recovered non-surgically on day 5 or day 6 after oestrus from Japanese Black cows after conventional superovulation treatment (Kojima et al., 1989). Blastomeres from embryos at the morula stage were used as nuclear donors.

Recipient oocytes were collected from several ovaries (mostly from Holstein and a few from Japanese Black) obtained from an abattoir. In these experiments, nuclear transfer was performed using recipient oocytes of undefined origin (UD-NT).

In a second series of experiments, the mtDNA origin of recipient oocytes was determined. Three pairs of ovaries were obtained and recipient oocytes were collected individually from each pair of ovaries. Nuclear transfer was performed using recipient oocytes of defined origin (D-NT). The mtDNA genotype of these ovaries was also determined.

Four additional pairs of ovaries were obtained and their oocytes were collected to compare the mtDNA genotype of an individual ovary with that of its oocytes.

\section{Nuclear transfer procedure}

Follicular oocytes collected from ovaries were matured in TCM-199 (Gibco BRL, Rockville, MD) supplemented with $10 \%(\mathrm{v} / \mathrm{v})$ heat-treated fetal calf serum (FCS). After $24 \mathrm{~h}$ maturation, the oocytes were enucleated and pretreated with a combination of $10 \mathrm{mmol}$ calcium ionosphere A23187 $\mathrm{l}^{-1}$ (Calbiochem, San Diego, CA) for $5 \mathrm{~min}$ and $10 \mu \mathrm{g}$ cycloheximide $\mathrm{ml}^{-1}$ (Sigma Chemical Co., St Louis, MO) for $6 \mathrm{~h}$, before fusion with a donor cell. Electrofusion was performed at $75 \mathrm{VDC}$ pulse $\mathrm{mm}^{-1}$ for $2 \times 50 \mu \mathrm{s}$ in Zimmerman mammalian cell fusion medium. The reconstituted embryos were cultured in CR1aa medium (Rosenkrans and First, 1994) for 7 days, as reported by Takahashi et al. (1996).

Nuclear transfer embryos that developed to the blastocyst stage in vitro were transferred non-surgically into recipient cows. D-NT embryos were produced using 30-cell stage morulae as donor cells to determine mtDNA heteroplasmy during early embryonic development. Each of three D-NT embryos was removed from culture at a different stage of embryo development: immediately after fusion, $48 \mathrm{~h}$ after fusion (the four- to eight-cell stage), and 7 days after fusion (the blastocyst stage). The mtDNA genotype of these embryos was analysed by the method described below.

\section{Nuclear transfer calves for analysis}

Twenty-one nuclear transfer calves were produced from UD-NT embryos. Eight of these cloned calves were selected for determination of mtDNA genotypes in the leucocytes or tissues (skeletal muscle, heart, testis or ovary, uterus, brain, liver, kidney, lung and spleen).

In addition, six nuclear transfer calves, consisting of two sets of triplets, were produced from D-NT embryos. These calves resulted from transfer into four and three recipients of eight and six D-NT blastocysts, respectively. Blastomeres from two embryos at the morula stage, consisting of 18 and 21 cells, were used as nuclear donors. The mtDNA genotypes of four D-NT calves were determined in various tissues (skeletal muscle, heart, testis, brain, liver, kidney, lung and spleen), and in the leucocytes of the other two calves. Genetic identity of triplet cloned calves was also confirmed by bloodtype analysis.

The mtDNA genotypes of donor cells were determined by analysis of the blood of Japanese Black cows from which the donor embryos had been collected. The mtDNA genotypes of recipient oocytes were determined by analysing the ovaries yielding the recipient oocytes. The mtDNA genotypes of nuclear transfer calves were compared with those of the donor cells and recipient oocytes.

\section{DNA extraction for $m t D N A$ analysis}

Leucocytes were purified from fresh blood treated with EDTA, followed by centrifugation ( $2000 \mathrm{~g}$ for $30 \mathrm{~min}$ ) and low hypotonic ( $37.5 \mathrm{mmol} \mathrm{NaCl}_{2} \mathrm{l}^{-1}$ ) treatment. The leucocytes and tissue samples were disrupted with lysis 


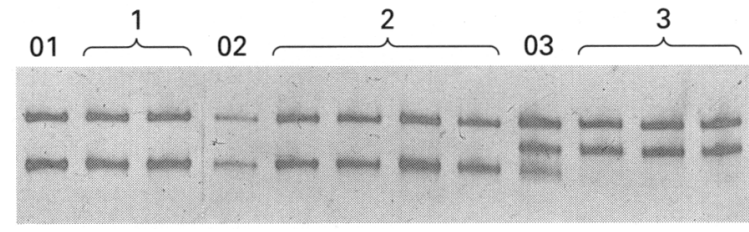

Fig. 1. mtDNA genotypes of bovine ovaries and their oocytes analysed by PCR-single-strand conformation polymorphism (SSCP) of SF and SR fragments. Lanes 01, 02 and 03: genotype of ovaries; lanes 1: oocytes collected from 01; lanes 2: oocytes collected from 02 ; and lanes 3: oocytes collected from 03 .

buffer $\left(1 \%(\mathrm{w} / \mathrm{v})\right.$ SDS, $10 \mathrm{mmol}$ Tris-Cl $\mathrm{l}^{-1}, \mathrm{pH} 8.0,5 \mathrm{mmol}$ EDTA ${ }^{-1}, 100 \mu \mathrm{g}$ proteinase $\mathrm{K} \mathrm{ml}^{-1}$ and $10 \mu \mathrm{g}$ RNase $\left.\mathrm{A} \mathrm{ml}^{-1}\right)$ at $37^{\circ} \mathrm{C}$ overnight. Total DNA was purified by phenolchloroform extraction and ethanol precipitation, and $100 \mathrm{ng}$ of each total DNA was used as templates for PCR-SSCP analysis.

Each sample from the reconstituted embryos, blastomeres and oocytes was washed nine times in Dulbecco's PBS without magnesium and calcium (Takara Shuzo Co., Tokyo) containing $1 \%(\mathrm{w} / \mathrm{v})$ polyvinylpyrrolidone and placed into $10 \mu 1 \mathrm{H}_{2} \mathrm{O}$ in $0.5 \mathrm{ml} \mathrm{PCR}$ tubes. The samples were frozen and thawed three times before PCR-SSCP analysis.

\section{mtDNA genotype analysis using $P C R-S S C P$}

mtDNA genotypes were determined by the PCR-SSCP method using two sets of primers, situated in the variable region and the whole region of the D-loop, respectively, to confirm the result from each PCR reaction. PCR-SSCP of the variable region allows detection of mutations and heteroplasmy on mtDNA, and PCR-SSCP of the whole Dloop allows detection of mutations that are not detected in the variable region.

The sequences of oligonucleotide primers used for PCR amplification of the variable region in the D-loop were as follows: SF (3'-CCATGCATATAAGCAAGTACATGAC-5') and SR ( 3 '-CTGATTAGCCATTAGTCCATCGAG-5'). The PCR amplification under 'hot start' conditions was performed in a $25 \mu \mathrm{l}$ reaction volume containing $12.5 \mathrm{pmol}$ of each primer, $1 \times$ PCR buffer (Promega Co., Madison, WI), 0.9 U Taq DNA Polymerase (Promega) pre-reacted with $0.23 \mu \mathrm{g}$ TaqStart antibody (Clontech Laboratories Inc., Palo Alto, CA), $0.2 \mathrm{mmol} \mathrm{dNTP} \mathrm{l}^{-1}$ and $1.5 \mathrm{mmol} \mathrm{MgCl}_{2} \mathrm{l}^{-1}$. The reaction mixture was incubated in a thermal cycler (Program temp control system PC-700, Astec Inc., Fukuoka) under the following conditions: $96^{\circ} \mathrm{C}$ for $1 \mathrm{~min}$ for first denaturing, 30 cycles of denaturing, annealing and extending $\left(95^{\circ} \mathrm{C}\right.$ for $1 \mathrm{~min}$ for denaturing, $65^{\circ} \mathrm{C}$ for $1 \mathrm{~min}$ for annealing and $72^{\circ} \mathrm{C}$ for $1 \mathrm{~min}$ for extending) and $72^{\circ} \mathrm{C}$ for $4 \mathrm{~min}$ for final extension. Each PCR product ( $1 \mu \mathrm{l}$; SF and SR fragment: $330 \mathrm{bp}$ ) was diluted one to three times with TE buffer $\left(10 \mathrm{mmol}\right.$ Tris- $\left.\mathrm{Cl} \mathrm{l}^{-1}, \mathrm{pH} 8.0,1 \mathrm{mmol}^{\mathrm{EDTA}} \mathrm{l}^{-1}\right)$ for SSCP analysis.

Two primers (M. P. Sabour, personal communication) were used for PCR amplification of the whole D-loop: LF (3'-TAATATACTGGTCTTGTAAACC-5') and LR (3'-AACA-
GTTAACAGGAAGGCTGGGACCAAACC-5'). The PCR procedure was as described by Harumi et al. (1994). The DNA fragments amplified by LF and LR primers were digested using the restriction enzyme HpaII (LF and LR fragments: $547 \mathrm{bp}, 353 \mathrm{bp}$ and $230 \mathrm{bp}$ ) and used for SSCP analysis.

For SSCP analysis, $1 \mu$ of each PCR product was mixed with $5 \mu \mathrm{l} 95 \%$ deionized formamide solution containing $20 \mathrm{mmol} \mathrm{EDTA}^{-1}$, incubated at $95^{\circ} \mathrm{C}$ for $5 \mathrm{~min}$ and chilled on ice for $10 \mathrm{~min}$. Each sample $(1 \mu \mathrm{l})$ was analysed on $5.5 \%$ $(\mathrm{w} / \mathrm{v})$ polyacrylamide gel $(8 \mathrm{~cm} \times 8 \mathrm{~cm} \times 0.1 \mathrm{~cm})$ containing $5 \%(\mathrm{v} / \mathrm{v})$ glycerol. The electrophoresis was performed in

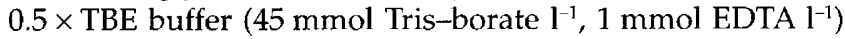
at $120 \mathrm{~V}$ for $5 \mathrm{~h}$ under controlled gel temperature at $4^{\circ} \mathrm{C}$ (Takeda et al., 1997). The resulting band patterns were visualized by silver staining (Silver Stain Plus Kit, Bio Rad Laboratories, Hercules, CA).

\section{Results}

The mtDNA genotypes of eggs were compared with those of the ovaries from which they were obtained by the PCR-SSCP method. Among four ovaries analysed, three ovaries showed homogeneous mtDNA patterns (Fig. 1). All the eggs from these ovaries had the same mtDNA genotype as the relevant ovary. The fourth ovary showed a heteroplasmic pattern and two different mtDNA genotypes, but oocytes obtained from the ovary had only one of the two types of mtDNA (Fig. 1).

The mtDNA genotype of each of the 21 UD-NT offspring was compared with the mtDNA genotype of the donor cell. All the mtDNA genotypes of UD-NT offspring were different from those of donor cells (Fig. 2), with only one exception (Fig. 2c). Most of the UD-NT offspring (17 calves) showed homoplasmy in their mtDNA genotypes (Fig. 2a), and three of the other four UD-NT offspring (two sets of cloned calves) had two kinds of mtDNA pattern (heteroplasmic), which were also different from the mtDNA of donor cells (Fig. 2c). However, one of these calves showed heteroplasmy and contained the same mtDNA genotype as its donor cell (Fig. 2c). Eight UD-NT calves with homoplasmic mtDNA genotypes were analysed to determine the mtDNA genotypes in various tissues (skeletal muscle, heart, testis or ovary, uterus, brain, liver, kidney, lung and spleen). The mtDNA band patterns of all of the tissues were the same in each cloned calf (Fig. 2b).

The mtDNA genotypes of six D-NT offspring (two sets of triplets) produced from oocytes with pre-determined mtDNA genotypes were compared with those of the recipient oocytes and donor cells. In all of the D-NT calves, only mtDNA genotypes that were also found in their oocytes were observed (Fig. 3a). The same results were obtained with the mtDNA genotypes of various tissues from four of the D-NT calves. In these calves, the mtDNA genotypes were the same as the oocytes and not the donor cells (Fig. 3b).

Patterns of mtDNA in D-NT embryos during early embryonic development were examined. The mtDNA genotypes of the embryos recovered immediately after fusion were heteroplasmic, consistent with the view that mtDNAs from both donor cells and recipient oocytes were 
(a)

(i)

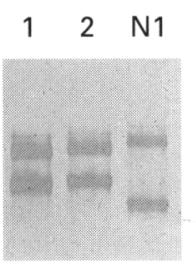

(ii)

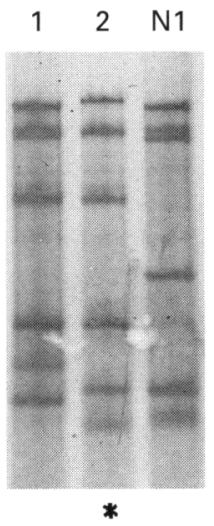

(b)
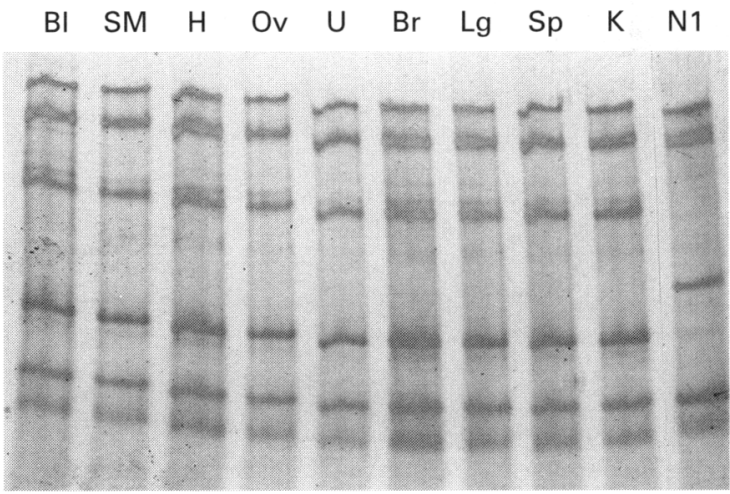

(c)

(i)

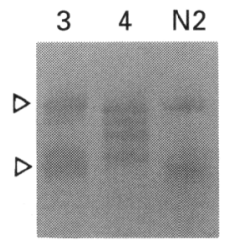

(ii)

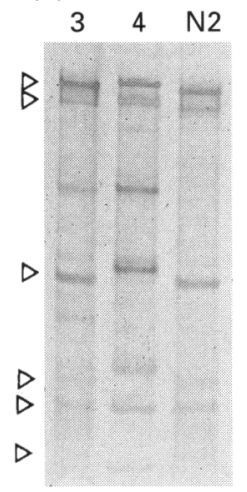

Fig. 2. mtDNA genotypes of calves produced by nuclear transfer using recipient oocytes of undefined origin (UDNT) analysed by PCR-single-strand conformation polymorphism (SSCP). (a) Unknown mtDNA genotype in UDNT calves: (i) SF and SR fragments; (ii) LF and LR fragments. Lanes 1 and 2: UD-NT calves produced from the same embryo as nucleus donors; N1: cow (blood) offered nucleus donor cells of 1 and 2. UD-NT calf 2 and its nucleus donor cell N1 appeared to be the same genotype by analysis (i), but were shown to be of different genotypes by analysis (ii). (b) mtDNA genotypes of various tissues of UD-NT calf 2 (shown by an asterisk on (a)), analysed by PCR-SSCP using LF and LR fragments. Bl, blood; SM, skeletal muscle; H, heart; Ov, ovary; U, uterus; $\mathrm{Br}$, brain; Lg, lung; Sp, spleen; K, kidney; lane N1: the nucleus donor cell of calf 2. (c) mtDNA heteroplasmy in UD-NT calves: (i) SF and SR fragments; (ii) LF and LR fragments. Lanes 3 and 4: UD-NT calves produced from the same embryo as nucleus donors, lane N2: cow (blood) offered the nucleus donor cells of 3 and 4 . Arrows show the same band patterns as the donor cells.

present. The amount of donor cell mtDNA decreased at the four- to eight-cell stage and was almost absent at the blastocyst stage (Fig. 4).

\section{Discussion}

Transmission of mtDNA genotypes to offspring is thought to be controlled by strict maternal inheritance (Gyllensten et al., 1985; Birkey, 1995). Moreover, different types of mtDNA segregate evenly in the female germ line due to a genetic bottleneck in early oogenesis. As a result, most individuals are homoplasmic and have a single mtDNA genotype (Hauswirth and Laipis, 1985; Jenuth et al., 1996). Hauswirth and Laipis (1982) reported two mitochondrial genotypes within one maternal lineage in Holstein cows. Pedigree analysis of mtDNA variants indicates that a rapid change of mtDNA genotypes occurs within only one or a few generations (Ashley et al., 1989; Koehler et al., 1991). A similar phenomenon was also observed in the present study: one of the ovaries analysed showed mtDNA heteroplasmy. However, different mtDNAs became segregated in each oocyte as a single mtDNA genotype, indicating that a rapid bottleneck might occur in mtDNA sequences within one generation. Although, this may be a rare occurrence, this phenomenon should be considered when mtDNA maternal lineage is analysed.

Steinborn et al. (1998b) detected a wide range $(0.0004-18 \%)$ of donor cell mtDNA in cloned calves using the allelespecific TaqMan PCR method. In the present study, only the 
(a)

(i)

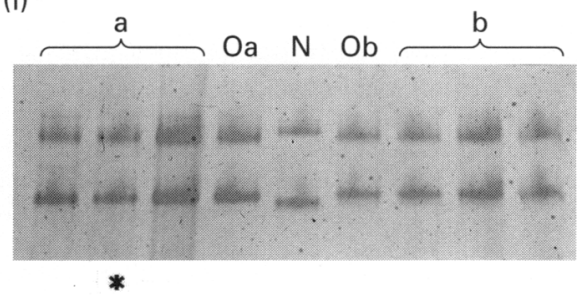

(ii)

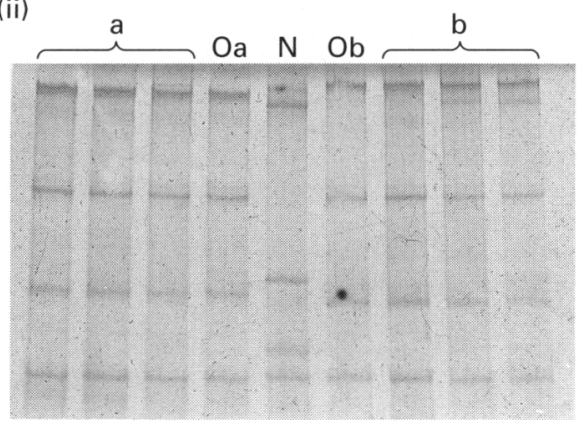

(b)

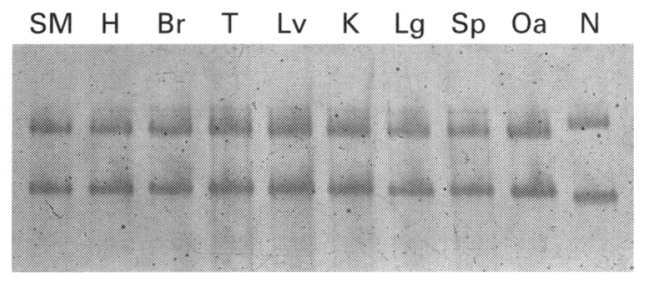

Fig. 3. mtDNA genotypes of calves produced by nuclear transfer using recipient oocytes of defined origin (D-NT) analysed by PCR-single-strand conformation polymorphism (SSCP). (a) Comparison of mtDNA genotypes with two sets ( $a$ and $b$ ) of D-NT triplets, the nucleus donor cells $(\mathrm{N})$ and the recipient oocytes (Oa and $\mathrm{Ob}$, respectively) analysed by $\mathrm{PCR}-\mathrm{SSCP}$ of $\mathrm{SF}$ and SR fragments (i) and LF and LR fragments (ii). (b) mtDNA genotypes of various tissues of a D-NT calf (shown by an asterisk on (a)), analysed by PCR-SSCP of SF and SR fragments. SM, skeletal muscle; $\mathrm{H}$, heart; $\mathrm{Br}$, brain; $\mathrm{T}$, testis; Lv, liver; $\mathrm{K}$, kidney; $\mathrm{Lg}$, lung; Sp, spleen; lane $\mathrm{N}$, the nucleus donor cell; lane $\mathrm{Oa}$, the recipient oocyte.

mtDNA genotype of recipient oocytes, not of donor cells, was detected in each of the D-NT calves, indicating that the mtDNA of D-NT calves originated from the recipient oocytes. Furthermore, the mtDNA genotype of donor cells was not detected in most of the UD-NT calves. Analysis of mixtures of DNA at several ratios revealed that the limit of detection of this method was $3-4 \%$, which was considered to be adequate for detection of the mixture of mtDNA in the reconstituted embryos in this study.

Four of 21 UD-NT offspring (representing two sets of clones) showed mtDNA heteroplasmy in their tissues. One set of clonal members came from the same litter and showed exactly the same band patterns, which were different from the donor mtDNA genotype. It is possible that rapid genetic

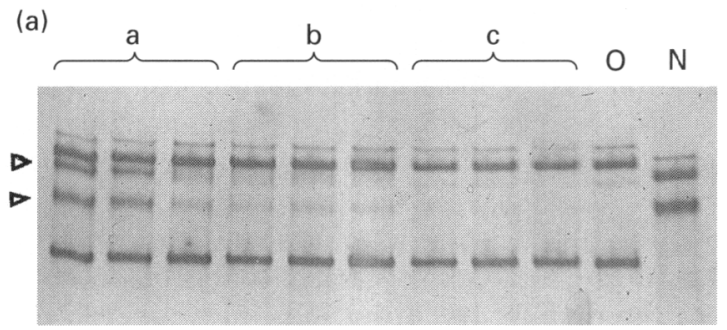

(b)

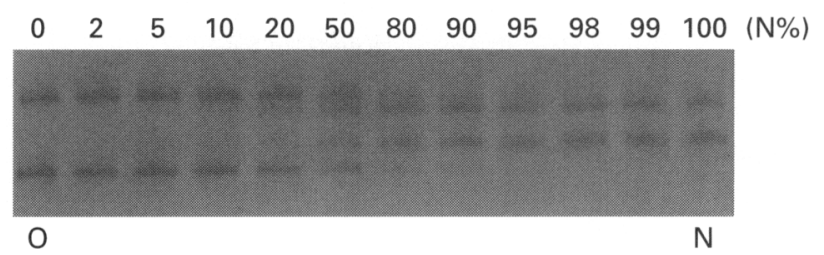

Fig. 4. Heteroplasmy in nuclear transfer bovine embryos analysed by PCR-single-strand conformation polymorphism (SSCP) of SF and SR fragments. (a) mtDNA genotypes of nuclear transfer embryos immediately after fusion (lanes a), $48 \mathrm{~h}$ after fusion (the four- to eight-cell stage) (lanes b), and 7 days after fusion (the blastocyst stage) (lanes c). Lane $\mathrm{O}$ : an oocyte collected from the same ovary; lane $\mathrm{N}$ : a blastomere collected from the same embryo. Arrows show the same patterns as the donor cells. (b) Analysis of mixtures of oocyte $(\mathrm{O})$ and blastomere $(\mathrm{N})$ DNAs at several ratios. Each PCR product was mixed and used as template DNA for the PCR-SSCP.

mutations are responsible for the heteroplasmic mtDNA genotype of these UD-NT calves. Alternatively, the heteroplasmy may be transmitted from the recipient oocyte, the mtDNA genotypes of which were originally heteroplasmic. The other clonal members were not from the same litter and showed different band patterns. One of these was the same as the donor mtDNA genotype. It is possible that the recipient oocyte had mtDNA heteroplasmy, including the same genotype as that of the donor cell. However, a similar phenomenon has been observed for intraspecific nuclear transplantation in mice (Meirelles and Smith, 1997) and cattle (Steinborn et al., 1998a). These investigations showed that the mtDNA from the karyoplast persists in the reconstituted embryos and in the resultant progeny.

mtDNAs from both the recipient oocyte and from the donor cell were detected in the D-NT embryos collected immediately after fusion of the karyoplast and the oocyte. However, the donor mtDNA decreased at the four- to eightcell stage and was hardly detectable at the blastocyst stage. These results explain why donor cell mtDNAs were not detected in most of the nuclear transfer calves, and indicate that the mtDNA originating from the donor blastomere was nearly eliminated during early embryonic development. This finding does not support the observations of Steinborn et al. (1998a), who reported neutral segregation of parental mtDNA in cloned bovine embryos during embryogenesis using embryos from Simmental cattle as donor cells. However, Steinborn et al. (1998b) also reported a reduction in donor cell mtDNA in one of the clones using embryos from 
the Brown Swiss breed as donor cells. In the present study, nuclear transfer embryos were produced using donor cells derived from Japanese Black cattle, the mtDNA sequence of which is also classified as Bos taurus; no unique differences are observed between Holstein and Japanese Black breeds (Watanabe et al., 1985; Kikkawa et al., 1995; Takeda et al., 1997). In these cases, it is possible that some unknown factors cause a reduction in donor cell mtDNA. This observation is similar to the finding that in bovine embryos fertilized in vitro the sperm mitochondria become undetectable at the late four-cell stage (Sutovsky et al., 1996). It has also been reported that specific elimination of sperm mtDNA from the fertilized egg occurs at the pronuclear stage in intraspecific mice hybrids (Kaneda et al., 1995). During bovine embryonic development, mitochondria show extensive morphological transformation (Plante and King, 1994). In bovine embryos, mitochondrial maturation begins at the eight-cell stage and is complete by the blastocyst stage. King et al. (1996) reported that in bovine nuclear transfer embryos, mature mitochondria that were probably carried along with the donor cells were observed at the one- to four-cell stages. It is speculated that mature mitochondria transferred with donor cells or spermatozoa may be broken down during morphological transformation of mitochondria in early development. In most cases in the present study, the mtDNA in the nuclear transfer calves was not derived from donor cells, but rather the mtDNA from the recipient oocytes was dominant.

There are reports on the relationship between mtDNA mutations and phenotypic expressions, such as disease (Wallace, 1992) and ageing (Soong et al., 1992) in humans, milk production in Holstein cows (Schutz et al., 1994) and carcass traits in Japanese Black cattle (Mannen et al., 1998). Nagao et al. (1998) reported that a mitochondrial congenic mouse carrying $M u$ s spretus mtDNA on a background of $M u s$ musculus (C57BL/6J) nuclear genome showed a phenotype of growth and physical performance, as measured by running on a treadmill until exhaustion, which was different from that of C57BL/6J mice. Possible interactions between mtDNA and the nuclear genome in intraspecific nuclear transfer are under investigation in nuclear transfer calves.

The authors wish to thank T. Kojima, H. Takahashi and H. Hanada for their support and suggestions, Y. Izaike, T. Suzaki and the staffs of the cattle-breeding farm for their help, and S. P. Leibo, C. S. Langham and M. P. Sabour (University of Guelph, Canada) for their assistance in preparing the manuscript. $S$ Takahashi and $\mathrm{H}$. Imai were supported by a grant from the Livestock Technology Association, Japan.

\section{References}

Ashley MV, Laipis PJ and Hauswirth WW (1989) Rapid segregation of heteroplasmic bovine mitochondria Nucleic Acids Research 17 7325-7331

Birkey CW (1995) Uniparental inheritance of mitochondrial and chloroplast genes: mechanisms and evolution Proceedings of National Academy of Sciences USA 92 11331-11338

Bondioli KR (1993) Nuclear transfer in cattle Molecular Reproduction and Development 36 274-275

Clayton DA (1984) Transcription of the mammalian mitochondrial genome Annual Review of Biochemistry 53 573-594
Greenberg BD, Newbold JE and Sugino A (1983) Intraspecific nucleotide sequence variability surrounding the origin of replication in human mitochondrial DNA Gene 21 33-49

Gyllensten U, Wharton D and Wilson AC (1985) Maternal inheritance of mitochondrial DNA during backcrossing of two species of mice Jounal of Heredity 76 321-324

Harumi T, Furukawa T, Awata T, Kumagai M and Yasue H (1994) Polymerase chain reaction-single strand confomation polymorphisms in D-loop region of the bovine mitochondrial DNA Animal Science Technology (Japan) 65 149-151

Hauswirth WW and Laipis PJ (1982) Mitochondrial DNA polymorphism in a maternal lineage of Holstein cows Proceedings of National Academy of Sciences USA 79 4686-4690

Hauswirth WW and Laipis PJ (1985) Transmission genetics of mammalian mitochondria: a molecular model and experimental evidence. In Achievements and Perspectives of Mitochondrial Research Vol. II: Biogenesis pp 49-59 Eds E Quagliariello, EC Slater, F Palmieri, C Saccone and AM Kroon. Elsevier Science Publishers, Amsterdam, New York, Oxford

Hecht NB, Liem H, Kleene KC, Distel RJ and Ho SM (1984) Maternal inheritance of the mouse mitochondrial genome is not mediated by a loss or gross alteration of the paternal mitochondrial DNA or by methylation of the oocyte mitochondrial DNA Developmental Biology 102 452-461

Horai S and Hayasaka K (1990) Intraspecific nucleotide sequence differences in the major noncoding region of human mitochondrial DNA American Journal of Human Genetics 46 828-842

Jenuth J P, Peterson AC, Fu K and Shoubridge EA (1996) Random genetic drift in the female germline explains the rapid segregation of mammalian mitochondrial DNA Nature Genetics 14 146-151

Kaneda H, Hayashi J, Takahama S, Taya C, Lindahl KF and Yonekawa H (1995) Elimination of paternal mitochondrial DNA in intraspecific crosses during early mouse embryogenesis Proceedings of National Academy of Sciences USA $924542-4546$

Kikkawa Y, Amano T and Suzuki H (1995) Analysis of genetic diversity of domestic cattle in east and southeast Asia in terms of variations in restriction sites and sequences of mitochondrial DNA Biochemical Genetics $3351-60$

King WA, Shepherd DL, Plante L, Lavoir MC, Looney CR and Barnes FL (1996) Nucleolar and mitochondrial morphology in bovine embryos reconstructed by nuclear transfer MolecularReproduction and Development $\mathbf{4 4}$ 199-506

Koehler CM, Lindberg GL, Brown DR, Beitz DC, Freeman AE, Mayfield JE and Myers AM (1991) Replacement of bovine mitochondrial DNA by a sequence variant within one generation Genetics 129 247-255

Kojima T, Soma T and Oguri N (1989) The effects of simplification of donor preparation, several superovulatory treatment by FSH-P and the single insemination regimen on embryo production in Japanese beef cattle Japanese Journal of Zootechnical Science 60 721-727

Lightowlers RN, Chinnery PF, Turnbull DM and Howell N (1997) Mammalian mitochondrial genetics: heredity, heteroplasmy and disease Trends in Genetics 13 450-455

Loftus RT, MacHugh DE, Bradley DG, Sharp PM and Cunningham P (1994) Evidence for two independent domestications of cattle Proceedings of National Academy of Sciences USA 91 2757-2761

Mannen H, Kojima T, Oyama K, Mukai F, Ishida T and Tsuji S (1998) Effect of mitochondrial DNA variation on carcass traits of Japanese Black cattle Journal of Animal Science 76 36-41

Meirelles FV and Smith LC (1997) Mitochondrial genotype segregation in a mouse heteroplasmic lineage produced by embryonic karyoplast transplantation Genetics 145 445-451

Michaels GS, Hauswirth WW and Laipis PJ (1982) Mitochondrial DNA copy number in bovine oocytes and somatic cells Developmental Biology 94 246-251

Nagao $Y$, Totsuka $Y$, Atomi $Y$, Kaneda $H$, Lindahl KF, Imai $H$ and Yonekawa H (1998) Decreased physical performance of congenic mice with mismatch between the nuclear and the mitochondrial genome Genes and Genetic Systems 73 13-19

Orita M, Iwahana H, Kanazawa H, Hayashi K and Sekiya T (1989) Detection of polymorphisms of human DNA by gel electrophoresis as single-strand conformation polymorphisms Proceedings of National Academy of Sciences USA 86 2766-2770

Plante L and King WA (1994) Light and electron microscopic analysis of bovine embryos derived by in vitro and in vivo fertilization Journal of Assisted Reproduction and Genetics 11 515-529 
Plante Y, Schmuts SM and Lang KDM (1992) Restriction fragment length polymorphism in the mitochondrial DNA of cloned cattle Theriogenology 38 897-904

Prather RS and First NL (1990) Nuclear transfer in mammalian embryos International Review of Cytology 120 169-190

Rosenkrans CF, Jr and First NL (1994) Effect of free amino acids and vitamins on cleavage and developmental rate of bovine zygotes in vitro. Journal of Animal Science 72 434-437

Schutz MM, Freeman AE, Lindberg GL, Koehler CM and Beitz DC (1994) The effect of mitochondrial DNA on milk production and health of dairy cattle Livestock Production Science 37 283-295

Soong NW, Hinton DR, Cortopassi G and Arnheim N (1992) Mosaicism for a specific somatic mitochondrial DNA mutation in adult human brain Nature Genetics 2318-329

Steinborn R, Zakhartchenko V, Jelyazkov J, Klein D, Wolf E, Müller M and Brem G (1998a) Composition of parental mitochondrial DNA in cloned bovine embryos FEBS Letters 426 352-356

Steinborn R, Zakhartchenko V, Wolf E, Müller M and Brem G (1998b) Nonbalanced mix of mitochondrial DNA in cloned cattle produced by cytoplast-blastomere fusion FEBS Letters 426 357-361

Sutovsky P, Navara CS and Schatten G (1996) Fate of the sperm mitochondria, and the incorporation, conversion, and disassembly of the sperm tail structures during bovine fertilization Biology of Reproduction 55 1195-1205

Suzuki Y, Sekiya T and Hayashi K (1991) Allele-specific polymerase chain reaction: a method for amplification and sequence determination of a single component among a mixture of sequence variants Analytical Biochemistry 19282-84

Takahashi S, Kubota C, Ogata Y, Tokunaga T and Imai H (1996) Parthenogenetic activation and development of bovine oocytes treated with protein synthesis or protein phosphorylation inhibitors Theriogenology 45 156

Takeda K, Onishi A, Takahashi S, Kojima T and Hanada H (1997) Genetic variants of bovine mitochondrial DNA D-loop region in Japanese Black, Japanese Brown and Holstein breeds Animal Science and Technology (Japan) $681161-1165$

Wallace DC (1992) Diseases of the mitochondrial DNA Annual Review of Biochemistry $611175-1212$

Watanabe T, Hayashi Y, Semba R and Ogasawara N (1985) Bovine mitochondrial DNA polymorphism in restriction endonuclease cleavage patterns and the location of the polymorphic sites Biochemical Genetics 23 $947-957$ 